\title{
Key pollen host plants provide balanced diets for wild bee larvae: A lesson for planting flower strips and hedgerows
}

\author{
Michał Filipiak
}

Institute of Environmental Sciences, Jagiellonian University, Kraków, Poland

\section{Correspondence}

Michał Filipiak

Email: michalOfilipiak@gmail.com

Funding information

Ministerstwo Nauki i Szkolnictwa Wyższego, Grant/Award Number: DS/WBiNoZ/INoŚ/

DS 761; Narodowe Centrum Nauki, Grant/

Award Number: 2016/21/B/NZ8/00318

Handling Editor: Romina Rader

\section{Abstract}

1. Bee-friendly plants are defined by the quantity of food they produce and the visitation rates of adult insects foraging for nectar. However, it is pollen nutritional quality that enables proper larval development of bees, affecting their populations. Not all plants produce pollen that satisfies the nutritional requirements of bee larvae, and we lack an understanding of how different plant pollens impact bee nutritional demands. This study examined whether nutritionally desirable key plant species may promote wild bee larval development, which is essential if the population is to thrive.

2. The generalist solitary mason bee Osmia bicornis L. was used as a model species to examine differences between bee larva nutritional demand and host plant nutrient supply; an ecological stoichiometry framework was applied. The stoichiometric ratios of 12 elements were investigated in bee bodies and cocoons (reflecting nutritional demand) and in the pollen supplied by the mother (nutritional supply; $N=15 \times 2$ sexes). Similarly, the stoichiometry of 62 pollen taxa, including native, alien, and garden plants and crops, was compared with the bee demand based on the literature.

3. Compared to males, females had higher demands for $\mathrm{P}, \mathrm{Cu}$ and $\mathrm{Zn}$ and were supplied with pollen richer in these elements. Therefore, when collecting pollen for their progeny, Osmia provides daughters and sons with different pollen mixtures, reflecting sex-specific nutritional demand.

4. Bees may be limited by the availability of $\mathrm{P}, \mathrm{Na}, \mathrm{Mn}, \mathrm{Mg}, \mathrm{K}, \mathrm{Fe}, \mathrm{Ca}, \mathrm{Zn}$ and $\mathrm{Cu}$, with high taxonomic variability in their concentrations in pollen. Female fitness may be particularly related to a high proportion of $\mathrm{P}$ in the diet.

5. Synthesis and applications. Access to key plant species that allow nutritionally balanced larval diets may be essential for bee development, whether food is gathered intentionally or randomly. Such plant species-and not only those rich in nectar and pollen-should be promoted in wild bee conservation efforts, including planting flower strips and hedgerows. Bee-friendly plants should not be defined and planted solely based on the quantities of food they produce and on the visitation rates of adult insects foraging for energy.

\section{KEYWORDS}

bee, conservation, ecology, food, health, nutrition, pollen, wild bee 


\section{1 | INTRODUCTION}

The nutritional needs of bee larvae differ from those of adults. Adult bees (feeding mostly on nectar) are energetically limited, whereas larvae are limited by the availability of body-building nutrients in their food (pollen). However, studies considering bee nutrition have focused mostly on adults. It is known that not all plants produce pollen that satisfies the nutritional requirements of bee larvae and that the pollen of specific plants mixed in the correct proportion may compose a balanced diet (Bukovinszky et al., 2017). Consequently, although floral diversity has been identified as an important factor for the fitness and population growth of pollinators (Cole, Brocklehurst, Robertson, Harrison, \& McCracken, 2017; Kaluza et al., 2017, 2018), the nutrient composition delivered to larvae is of paramount importance to ensure healthy development of individuals and growth of populations (Filipiak, 2018; Vaudo, Tooker, Grozinger, \& Patch, 2015).

The framework of ecological stoichiometry (or biological stoichiometry) is a promising approach to this issue. It allows questions about the most basic mechanism shaping the nutritional ecology of bees, i.e. balancing the larval diet to enable larval growth, development and pupation into the adult body equipped with all the structures needed for maximal fitness (Filipiak, 2018). The growth and development of every cell, tissue, organism and population is subject to the law of conservation of mass. Thus, organisms build their bodies by relying on thousands of chemical reactions, all of which must be chemically balanced. This rule is similar to the case of a single chemical reaction, in which the atomic composition of the reactants is identical to the atomic composition of the products (Sterner \& Elser, 2008). Therefore, insufficient concentrations of certain atoms in food prevent the production of tissues and physiologically important molecules that are constructed from this food either by the consumer itself or by its microbiota. The demand for resources used for growth and development is reflected in organismal stoichiometry (Kay et al., 2005), i.e. the elemental phenotype of an organism (Jeyasingh, Cothran, \& Tobler, 2014). Organismal stoichiometry is homeostatic and species-specific because it is a consequence of the particular structure, physiology and metabolism of different taxa (Bartrons, Sardans, Hoekman, \& Peñuelas, 2018; González et al., 2018; Sterner \& Elser, 2002). The degree of stoichiometric homeostasis is higher in heterotrophs than in autotrophs (Sterner \& Elser, 2002) and may be higher for macroelements than for microelements (Bradshaw, Kautsky, \& Kumblad, 2012).

Under these conditions, there is intraspecific variation in organismal stoichiometry, but it always remains within the limits of stoichiometric homeostasis specified by trophic position and phylogeny (Bartrons et al., 2018; González et al., 2018; Leal, Seehausen, \& Matthews, 2017). Within this context, a mismatch between the atomic ratios of an organism's adult body and its larval food is expected to have negative fitness consequences (Kay \& Vrede, 2008; Kay et al., 2005). This phenomenon is called stoichiometric mismatch and is mathematically understood as much lower atomic proportions of $C$ :any other element in the consumer's body than in its food (Denno \& Fagan, 2003). Considering the framework of ecological stoichiometry, the quantity of food provided to bee larvae cannot substitute for its quality, and the observed toxic effects of a particular diet on an organism may be caused by stoichiometric mismatch rather than by toxic substances (Jones \& Flynn, 2005). Bees may have almost infinite access to energy-rich food (nectar) that suits the nutritional needs of energetically limited adults. However, their populations and communities may be shaped by nutritional limitations experienced during the larval life stage resulting from inadequate nutritional composition of pollen.

This study investigated (a) the demand of growing bees for highquality food as body-building material and (b) the supply of bodybuilding nutrients in potential bee food, i.e. pollen of various plant species. It was hypothesized that due to taxonomic variability in pollen stoichiometry, the use of random pollen as a food source by bees would result in severe stoichiometric mismatch. Within this context, the role of floral diversity, especially the accessibility of nutritionally desirable key species, was assessed as a factor in promoting adequate nutritional balance in bees. This study is an important step in understanding the role of pollen stoichiometric quality in shaping bee populations, and it provides the foundation for future experimental studies to better understand the nutritional supply of various pollens to bees. The study provides, for the first time, critical information on the nutritional quality of different pollen species for wild bees. The findings can be used by stakeholders, landowners, farmers and producers of bee-friendly seed mixes to compose proper mixes of plant species for flower strips and hedgerows and when designing agrienvironmental strategies that promote floral food resources for bees.

\section{MATERIALS AND METHODS}

The concentrations and stoichiometry of 12 elements (C, N, S, P, $\mathrm{K}, \mathrm{Na}, \mathrm{Ca}, \mathrm{Mg}, \mathrm{Fe}, \mathrm{Zn}, \mathrm{Mn}$ and $\mathrm{Cu}$ ) in the total production (body and cocoon) of Osmia bicornis in both sexes and in the larval food (pollen) from which this production was made were investigated. Stoichiometric mismatches were calculated to determine which elements are scarce in pollen but required to a high degree by the bee and thus limit its development and growth.

A wild native population of the solitary mason bee, O. bicornis L., was chosen as a model system. As a generalist species that uses a variety of plants as food sources, this bee is suitable for studying the impact of the quality of food resources upon bees (Filipiak, 2018).

\section{1 | Study design}

The O. bicornis trap nest was established in an experimental garden at the Institute of Environmental Sciences, Jagiellonian University (Kraków, Poland; 5001'35"N, 1954'05"E; elevation: 213 m a.s.l.; mean annual temperature: $8.7^{\circ} \mathrm{C}$; mean annual precipitation: $679 \mathrm{~mm}$ ). The feeding experiment was performed under natural conditions in which O. bicornis specimens developed on pollen gathered from the naturally available pollen pool and provisioned by their mothers. The trap nest consisted of 460 empty Phragmites sp. stems of various sizes that were mounted in a wooden case and 
protected from rain (tarp cover) and predators (only the front side, which was covered with mesh, was open). Bee larvae were provisioned by mothers with pollen from plants that were in bloom during the course of the study. The species composition of available flowering plants changes throughout the season; therefore, to ensure that uniform pollen loads were delivered to bees, only nests established over 2 weeks were studied, between 1 and 15 May 2014. At the end of the experiment (15 May), stems that were not settled, not filled completely, and not closed by mothers with mud chop (which indicates finished nesting) were removed. Among the completely filled stems, 30 stems were chosen randomly, of which 15 were used for pollen supply collection and 15 were left to allow the bees to develop to maturity. From every stem chosen for pollen supply collection, two pollen loads were acquired: the one furthest from the stem entrance that had an egg laid on the top (female) and the one nearest to the stem entrance that had an egg laid on the top (male). If the pollen supply had no egg on top, it was not considered, and the nearest pollen supply with an egg was used instead. Eggs were separated from pollen for pollen analyses. Similarly, after 3 months, two cocoons that contained adult specimens were collected from every stem left for bee development: one containing the female inhabiting the cell furthest from the stem entrance and one containing the male inhabiting the cell closest to the stem entrance. Each adult body together with its cocoon was considered to be the total production of the bee based on the supplied pollen and is hereafter referred to as "production." Growing bees demand all the elements required for production in adequate proportions; thus, the elemental composition of the production is called the "demand." Similarly, the elemental composition of the pollen supplied by the mother, which constitutes the only food source for developing bees, is termed the "supply." To determine the stoichiometric mismatch between bee demand and supply, the concentrations of 12 elements (C, N, S, P, K, Na, $\mathrm{Ca}, \mathrm{Mg}, \mathrm{Fe}, \mathrm{Zn}, \mathrm{Mn}$ and $\mathrm{Cu}$ ) in the production of two sexes of $\mathrm{O}$. bicornis and in the pollen provisioned by their mothers were measured. Measurements were collected from a total of 60 samples (15 samples representing demand and 15 samples representing supply for each sex).

\subsection{Chemical analyses}

The $\mathrm{C}, \mathrm{N}$ and $\mathrm{S}$ concentrations were determined using a Vario EL III automatic CHNS analyser; the $\mathrm{K}, \mathrm{Ca}, \mathrm{Mg}, \mathrm{Fe}, \mathrm{Zn}, \mathrm{Mn}, \mathrm{Cu}$ and $\mathrm{Na}$ concentrations were determined using atomic absorption spectrometry (Perkin-Elmer AAnalyst 200 and Perkin-Elmer AAnalyst 800 ); and the $\mathrm{P}$ content was determined by colorimetry (MLE FIA). The samples were ground and homogenized using a mortar and coffee grinder and freeze-dried to a dry mass. From each ground and homogenized sample, two analytical subsamples were obtained: (a) a liquid solution subsample suitable for analysing the concentrations of $\mathrm{K}, \mathrm{Ca}, \mathrm{Mg}, \mathrm{Fe}, \mathrm{Zn}, \mathrm{Mn}, \mathrm{Cu}, \mathrm{Na}$ and $\mathrm{P}$ and (b) a subsample with which to directly analyse the $C, N$ and $S$ concentrations.

\section{3 | Trophic stoichiometric ratio-the measure of stoichiometric mismatch for bees feeding on various pollen species}

The trophic stoichiometric ratio (TSR; Filipiak \& Weiner, 2017) was used to identify pollen species imposing stoichiometric mismatches on $\mathrm{O}$. bicornis and therefore limiting bee growth and development:

$$
\operatorname{TSR}_{X}=(C: X)_{\text {food }} /(C: X)_{\text {consumer }},
$$

where $C$ is the carbon concentration and $X$ is the concentration of element $x$. The assimilation efficiency (AE) of atoms is assumed to be a maximum (100\%) except for carbon (lost to respiration; $A E$ 25\%). Thus, $T S R \geq 1 / 0.25$ (TSR $\geq 4$ ) indicates stoichiometric mismatch. The explanation and rationale for using the TSR is presented in the Supplement (Appendix S1). Note that the TSR conservatively assumes the assimilation of $100 \%$ of available noncarbon elements; therefore, in natural situations, the limitations may be stricter and will not be less strict than those estimated using the TSR.

In this study, the TSR values were calculated for bees feeding on (a) the pollen supply provisioned by their mothers, i.e. pollen on which they fed in reality and (b) pollen produced by various plant species for which data on elemental composition are available, i.e. random pollen that theoretically might be available.

In case (1), data were gathered in the field experiment in which the bees did not directly feed on the pollen provisions that were chemically analysed; instead, the measurements were conducted using randomly selected, representative pollen provisions from the pool available to the developing bees. Therefore, to assess the possibility that the pollen compositions provided to the bees by their mothers imposed limitations on production, a randomization procedure was applied, and the TSR values were calculated from the C: $X$ ratios of $30(15 \times 2$ sexes) measured pollen loads and $30(15 \times 2$ sexes) measured bee total productions. These values were randomly drawn from the distributions of the measured elemental contents for bees and pollen. For each sex, the total number of calculated TSR values was $15 \times 15=225$.

In case (2), the potential of the specific floral composition forming the available food base to shape the bee population was investigated. The available data on the pollen stoichiometry of various plant species, presented in Filipiak et al. (2017) (table S6), were used. From this dataset ( 85 pollen taxa compiled from 14 studies published in the past 75 years), 62 pollen taxa that occur within the area inhabited by O. bicornis were chosen for further investigation (including wild native species, alien species and plants cultivated in gardens and crops; the full list is given in Table S1). The data on the pollen stoichiometry of various plant species were used as the numerator to calculate the TSRs for these plant species. The TSR values were calculated using the reported mean concentrations of non-C elements in pollen calculated for a single species/genotype/collection site in a single study, as presented in table S6 by Filipiak et al. (2017). Carbon concentrations were not reported; therefore, the mean $\mathrm{C}$ concentration in pollen measured in this study provided for both sexes $(46.1 \%$ dry matter; $N=30, S D=1.56$ ) 
was used. Similar to case (1), the concentrations of elements in the bee total production measured in this study were used in the denominator; therefore, $15 \mathrm{C}: \mathrm{X}$ ratios were possible in the denominator. In the numerator, where literature data on pollen were used, various combinations were possible, depending on pollen species and element, ranging from 1 to 26 . Therefore, the total number of calculated TSR values could vary from $15(1 \times 15)$ to $390(26 \times 15)$. From these numbers for every pollen species and element, the same number of 225 TSR values was calculated, exactly as in case (1), to enable the appropriate comparison of values and descriptive statistics (medians, percentiles) between calculations performed in cases (1) and (2). Based on the calculated TSR values, (a) pollen taxa that may promote stoichiometric balance in the O. bicornis larval diet and (b) pollen taxa that are highly unbalanced for O. bicornis were identified. For (a), the concentrations of at least five elements were given, and at most one of them was limiting for any sex. For (b), at least three elements were limiting for at least one sex. They are shown in Table S1.

Total production includes the adult body and cocoon and was used for the calculations because it represents the total amount of every nutrient that was assimilated from food by the larva during development. A correctly developed adult body and cocoon are both required to increase the chances of survival and maximize individual fitness.

\subsection{Statistical analysis}

The Mann-Whitney $U$ test (Statistica 13) was used to assess the significance $(p<0.05)$ of differences between sexes in the concentrations of elements in bee-supplied pollen (supply) and bee production (demand).

PERMANOVA ( $\mathrm{R}$ 3.5.2 with vegan 2.5-4; Oksanen et al., 2019; $\mathrm{R}$ Core Team, 2018) was used to test whether the sexes are significantly differentiated in multielemental stoichiometry, with tests run separately for demand and supply. To further investigate which elements are most responsible for this differentiation, principal component analysis was performed on a correlation matrix (PCA, Canoco 5 ), and to assess the differences among the indicated clusters of sexes, independent $t$ tests ( $p<0.05$; Statistica 13) were computed for the 1st and 2nd PCA axis scores. Levene's test was used to check whether the variances of two groups were heterogeneous and to choose between pooled and separate variance $t$ tests.

The complete dataset is presented in the Supplement.

\section{3 | RESULTS}

\section{1 | Stoichiometric mismatch and the limitation of bee growth and development}

The calculations for various pollen species (Figure 1) indicate that the scarcity of 10 elements ( $\mathrm{Mn}, \mathrm{P}, \mathrm{Na}, \mathrm{Mg}, \mathrm{K}, \mathrm{Fe}, \mathrm{Ca}, \mathrm{Zn}, \mathrm{Cu}$ and $\mathrm{N})$ in pollen impacts bee growth and development. The comparison of TSR values calculated for the pollen supplied to the bees by their mothers with those calculated for random pollen species indicated considerable differences in TSR variability for $\mathrm{P}, \mathrm{K}, \mathrm{Na}, \mathrm{Fe}, \mathrm{Zn}$,
$\mathrm{Mn}$ and $\mathrm{Cu}$ (Figure 1; details in Figure S1). For these elements, the TSRs calculated for bee-collected pollen tended to be nonlimiting, whereas those calculated for the random species had high variance with a considerable number of limiting values. Osmia-collected pollen showing unbalanced concentrations of $\mathrm{Mg}$ and $\mathrm{Ca}$ for both sexes and $\mathrm{Mn}$ for females was nutritionally balanced for eight other elements (see Figure S1 for statistics). Therefore, Osmia-collected pollen meets the nutritional needs of $O$. bicornis to a greater extent than does pollen produced by random plant species.

\section{2 | Stoichiometric mismatches depend on pollen species and on bee sex}

Different pollen species imposed various stoichiometric mismatches on the bees (Figure 1; details in Figure S1 and Table S1). Sulphur was the only element for which bee demand was met by every studied pollen taxon. Of the 62 studied pollen taxa, 30 were indicated as highly limiting (three or more elements had limiting concentrations for at least one bee sex), and 25 taxa showed sex-dependent limiting effects (Table S1). The highly limiting plants for O. bicornis included crops, e.g. Brassica napus (rapeseed), Helianthus annuus (sunflower) and Zea mays (maize), and plants indicated as "bee-friendly": Lavandula sp. (lavender), Centaurea solstitialis (knapweed), Salix sp. (willow) and Taraxacum vulgare (dandelion). Native, alien and cultivated plants were suggested to promote the nutritional balance of the $O$. bicornis larval diet (Table S1). The most important were Trifolium (clover) with the exception of T. balance, Vicia faba (broad bean), Hypericum perforatum (St John's wort), Rubus ulmifolius (native blackberry), Juglans nigra (walnut) and Camellia japonica (common camellia) (Table S1).

\subsection{Sexual dimorphism in bee demand and supply stoichiometry}

\subsection{1 | Demand}

The concentrations of $\mathrm{C}$ and $\mathrm{N}$ in dry mass did not differ between sexes with respect to bee demand (Figure 2, see Supplement for details), but the percentage of $P$ in dry mass was sex-dependent and higher for females. Statistically significant differences were also found between sexes for the concentrations of $\mathrm{K}, \mathrm{Na}, \mathrm{Zn}$, $\mathrm{Mn}$ and $\mathrm{Cu}$ (Figure 2, see Supplement for details). Since the sexes were significantly differentiated in multielemental stoichiometry (PERMANOVA; $R^{2}=0.190$, pseudo- $F=6.587, p=0.001$ ), the proportional contribution of each element to the stoichiometric relationships in bee production was revealed by PCA (Figure 3). The first two principal components (axes) explained $36.69 \%$ of the observed variance in elemental concentrations. The bees formed two groups according to their sex that were shifted diagonally. The elements that contributed most to this shift were $\mathrm{K}$ and $\mathrm{Na}$, which loaded the 1st axis to the highest degree (loadings are represented by vectors in Figure 3, and the length of the vector corresponds to its load), but their vectors had opposite directions ( $\mathrm{Na}$ was highly concentrated in males with 1 st axis loading of 0.85 , and $\mathrm{K}$ 


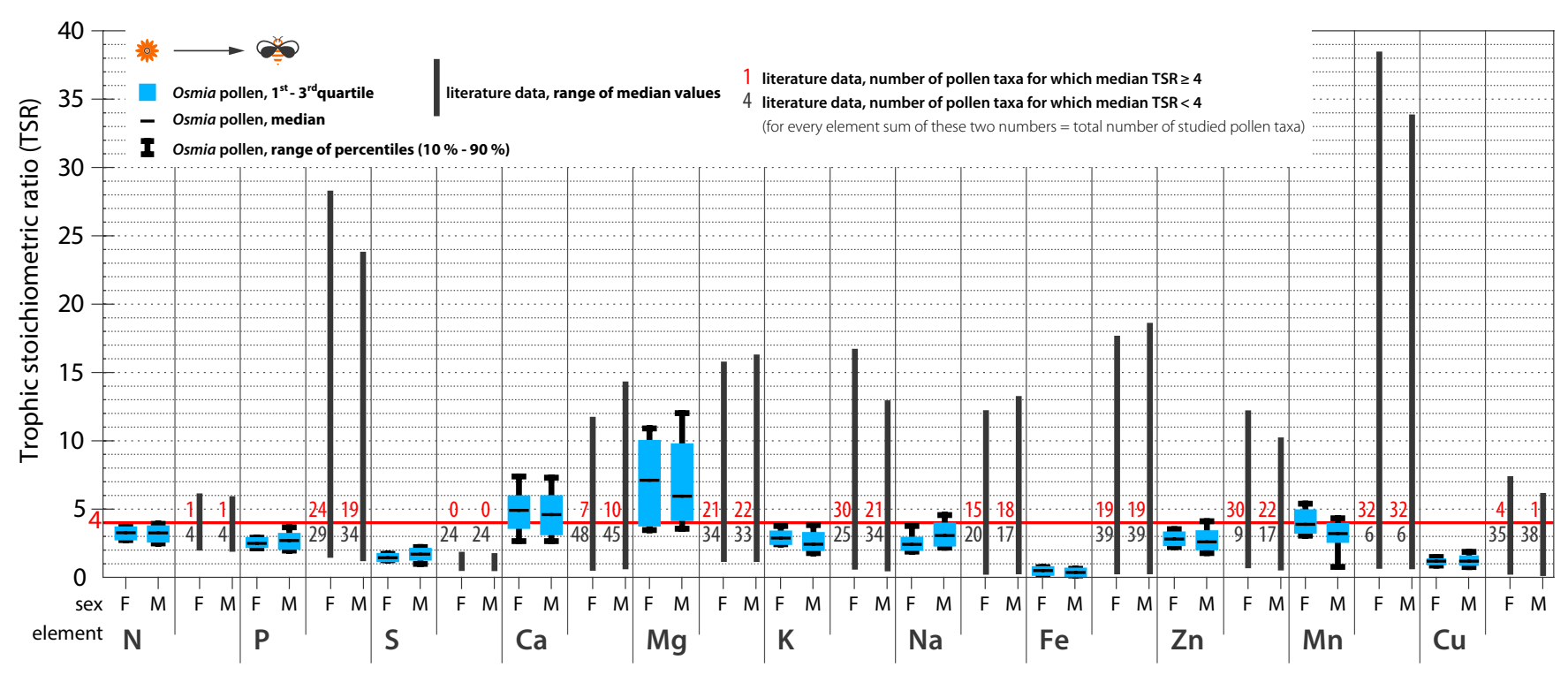

FIGURE 1 Use of random pollen may result in severe stoichiometric mismatch. The growth and development limitation was calculated as the trophic stoichiometric ratio $(T S R=(C: X)$ Supply $(C: X)$ Demand; $C=C$ concentration, $X=$ concentration of element $x$ ) for the studied elements. The red line indicates the threshold value of TSR $=4$, and TSR $\geq 4$ indicates a limitation on bee production due to the scarcity of the element in the pollen supply. Sex symbols: $\mathrm{F}$ - female, $\mathrm{M}$ - male. $\mathrm{N}=225$ for each sex. See Figure S1 for detailed analysis. The comparison of stoichiometric mismatches experienced by bees feeding on pollen provided by their mothers with those imposed by the elemental composition of random pollen species reveals high variation in the TSR values for random pollen and low variation in those for Osmia-supplied pollen loads. Bee and flower graphics: Vecteezy.com

was highly concentrated in females with 1st axis loading of 0.82 ). Other elements that greatly contributed to the observed diagonal shifting of the sexes were $\mathrm{Zn}$ (1st axis loading of 0.47 and 2 nd axis loading of 0.44), P (0.19 and 0.71) and $\mathrm{Cu}(0.70$ and 0.05). These three elements had relatively high concentrations in female production compared with male production. Therefore, the elements that most contributed to the observed sexual dimorphism in the stoichiometry of bee nutritional demand were $\mathrm{K}, \mathrm{Na}, \mathrm{Zn}, \mathrm{P}$ and $\mathrm{Cu}$. Females showed lower variance than males in the multielemental composition of production (Levene's test, $p<0.05$ ), i.e. females were more homeostatic in their elemental composition than males (Figure 3).

\subsection{2 | Supply}

The concentrations of $\mathrm{C}$ and $\mathrm{N}$ in the supply did not differ between the bee sexes (Figure 2, see the Supplement for details), but the concentration of $\mathrm{P}$ in the dry pollen mass was higher for females (Figure 2, see the Supplement for details). Statistically significant differences were also found between bee sexes for the S, Zn and $\mathrm{Cu}$ concentrations in the supply (Figure 2, see the Supplement for details). The sexes were not significantly differentiated in multielemental stoichiometry (PERMANOVA; $R^{2}=0.066$, pseudo- $F=1.983$, $p=0.14$ ); however, considering PCA, phosphorous substantially contributed to the observed diagonal shifting, revealing high loadings for both axes (1st axis loading: 0.48; 2nd axis loading: 0.75; explained was $39.29 \%$ of the observed variance in elemental concentrations; Figure 3). Furthermore, the C:P ratio of supply provided to females was lower than that provided to males (see supplementary P-discussion). The description and discussion of results considering the requirement of female bees for a P-rich diet is presented in the Supplement (Appendix S2).

\section{DISCUSSION}

Stoichiometric mismatches for N, P, Ca, Mg, K, Na, Fe, Zn, Mn and Cu may occur if bee larvae feed on particular pollen species (details: Figure 1 and Figure S1; Table S1). As a consequence, larval growth and development may be limited, negatively affecting the condition, health, fertility and fitness of the adults developing from nutritionally limited larvae (Kay \& Vrede, 2008; Kay et al., 2005; Sterner \& Elser, 2002). The stoichiometric mismatches calculated for the pollen supply provided to the bee larvae by their mothers were considerably lower and less variable than those suggested by the general trend for various pollen species (Figure 1; details in Figure S1). These results suggest that bees may either (a) be selecting specific plant species to enable stoichiometric balance of larval diets or (b) be only found in areas where plant communities provide an adequate stoichiometric balance. Consequently, if the floral composition of the bee habitat contains easily accessible but solely stoichiometrically unbalanced pollen, the bee community may be negatively impacted even if large amounts of pollen and nectar are available, influencing the bee distribution and population dynamics (Leroux et al., 2017). Therefore, irrespective of the foraging preferences of adult bees gathering nectar for themselves, O. bicornis populations can thrive 

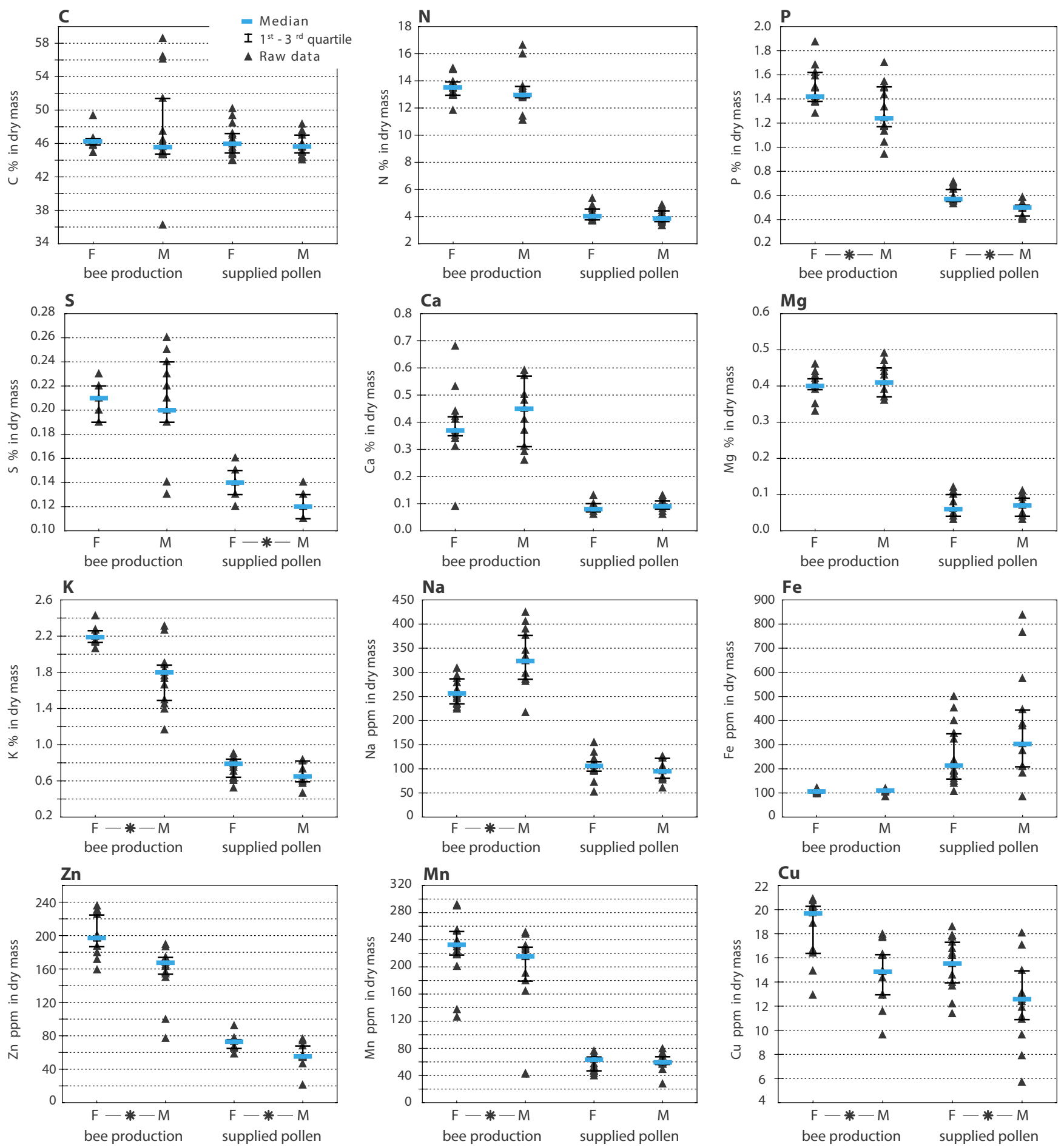

FIGURE 2 Concentrations of elements composing the bee supply (pollen) and the demand (bee production, i.e. body + cocoon) for nutrients. Sex-related differences in the concentration of each element were tested separately for demand and supply (Mann-Whitney $U$, $p<0.05, N=30$ ). Statistically significant differences are noted with an asterisk. Detailed results and statistics are shown in the Supplement

and prosper only in areas where plant communities provide nutritionally adequate larval food. Within this context, the occurrence of key plant species that provide a dietary stoichiometric balance for bee larvae (e.g. Brassica kaber (syn. Sinapis arvensis), Trifolium repens, V. faba, R. ulmifolius and J. nigra; see Table S1 for more) may be a factor in shaping bee populations. Therefore, the floral composition rather than the floral diversity of an inhabited area may shape bee populations via the nutritional supply available to bees. Indeed, the species composition of the pollen supplied for progeny influences offspring size and survival (Bukovinszky et al., 2017).

There are several limitations to this study that need to be overcome in future work. Given the limited sample size in this study, it 

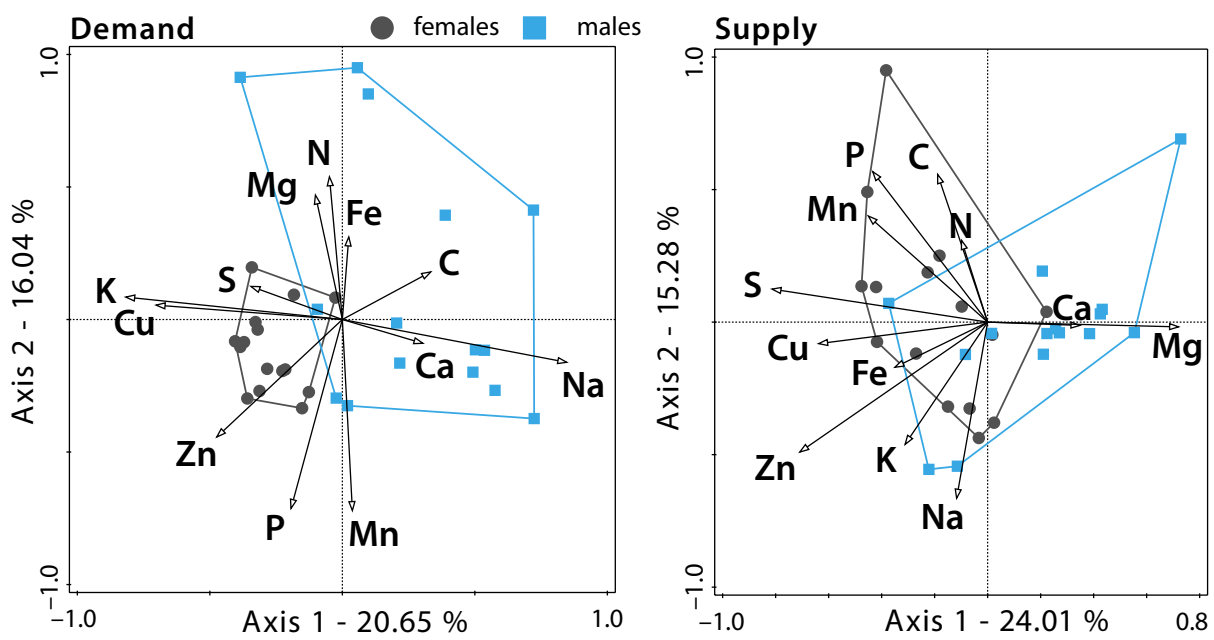

FIGURE 3 Multielemental stoichiometry of nutritional demand of bees and supplied pollen. PCA plots, $N=15$ for each sex. Statistically significant difference between sexes was revealed for demand (PERMANOVA; pseudo- $F=6.587, p=0.001$ ) but not for supply (PERMANOVA; pseudo- $F=1.983, p=0.14$ ). The first two axes are presented, and the percentage of explained variance is given for each. The patterns shown in the graphical PCA representation were confirmed by separate variance $t$ tests computed independently for the 1 st and 2 nd axis scores $(p<0.05)$. Statistical significance shifted along the 1 st axis for demand and along both axes for supply. Detailed results are shown in the Supplement. High concentrations of $\mathrm{P}, \mathrm{Cu}$ and $\mathrm{Zn}$ relative to those of other elements accounted for the differentiation of both the demand and supply of females from those of males. Females were more homeostatic in their demand, i.e. in the multielemental composition of production, than males (Levene's test, $p<0.05$ )

is possible that considering bee specimens originating from different populations would result in greater variation in the measured concentrations of elements. However, stoichiometric homeostasis predicts species-specific organismal stoichiometry that additionally suits a particular trophic group, even though intraspecific variation exists (Bartrons et al., 2018; González et al., 2018; Sterner \& Elser, 2002). Nonetheless, future studies are needed to verify this. Another weakness of the study is that the literature dataset on the elemental composition of different pollens comprises different studies performed at different locations and using various methods, which may explain part of the variance in the obtained results. The majority of pollen species were investigated in a single study, and only some had data collected in 2-5 studies (see Table S1 for details). Therefore, the TSRs calculated here for various pollen species are likely variable in precision.

Sex-related differences were found in the demand for specific nutrients required for bee production, which were partially reflected in the pollen supply stored by female bees for their progeny. Specifically, the concentrations of $\mathrm{P}, \mathrm{Cu}$ and $\mathrm{Zn}$ were higher for female than male demand and supply, and the differences in the demand for $\mathrm{Mn}, \mathrm{K}$ (higher for females) and $\mathrm{Na}$ (higher for males) were not reflected in the supply (Figures 2 and 3). Additionally, the limiting effect of feeding on pollen produced by 25 plant taxa was dependent on bee sex (Table S1). Because females and males differ in the multielemental stoichiometry of their production, they also have different nutritional needs for attaining a stoichiometrically balanced diet (Morehouse, Nakazawa, Booher, Jeyasingh, \& Hall, 2010). Accordingly, the sexes require food supplies of different stoichiometric quality to maximize their fitness. This difference might explain the sex-specific reproductive investment of female bees that collect pollen mixtures with different concentrations of $\mathrm{P}, \mathrm{Cu}$ and $\mathrm{Zn}$ for their daughters than for their sons. Therefore, O. bicornis might balance the larval diet in a sex-specific manner. An alternative explanation is possible: during the 2 weeks of the field study, different plant spectra were flowering at different times. Therefore, female cells, which were provisioned first, could contain different pollen spectra than male cells, which were provisioned last. However, such a mechanism would result in random changes in the nutritional composition of the collected pollen. The observed differences correlated with the specific nutritional needs of both sexes; therefore, these differences are unlikely to be caused solely by random effects. Regardless of the pollen spectra available through the 2-week period of the field study, O. bicornis showed a tendency to prefer pollen species fulfilling sex-specific nutritional larval needs. The reason for the failure of the supply to reflect sex differences in demand for $\mathrm{K}$, $\mathrm{Na}$ and $\mathrm{Mn}$ can only be speculated and might be either inadequate floral composition or weaker negative effects imposed on bee fitness by $\mathrm{K}, \mathrm{Na}$ and $\mathrm{Mn}$ scarcity in larval food than by $\mathrm{P}, \mathrm{Zn}$ and $\mathrm{Cu}$ scarcity. The sex-related differences in the biochemistry and chemical physiology of O. bicornis were reported previously (Strachecka et al., 2017). Further studies are needed to determine whether this mechanism occurs in various bee populations.

This study has shown that bee growth and development is limited by food quality regardless of the food quantity. These findings are relevant to the management of bees, in particular, the choice of plant species in agri-environmental schemes. For example, these findings may explain why wild bees do not use plant species sown in wildflower seed mixtures as pollen sources, as shown by Gresty et al. (2018). Gresty et al. (2018) concluded that plant species currently promoted by agri-environmental schemes are not optimal for solitary bees. The attractiveness of 
wildflower mixtures for wild bees depends on several key plant species (Warzecha, Diekötter, Wolters, \& Jauker, 2018). Floral resource quality may thus be one factor that mediates floral choice in flower strips. Taking all of these factors into consideration, the present study may be an important first step for identifying and promoting optimal plant species in agri-environmental schemes, but detailed studies considering inter- and intraspecific differences in the nutritional quality of various pollens for various bee species are needed.

Key foraging resources for pollinators are provided by different habitats to various degrees (Cole et al., 2017), and resource shortages may occur in agricultural landscapes (Jachula, Denisow, \& Wrzesien, 2018), resulting in a decrease in bee survival (Requier, Odoux, Henry, $\&$ Bretagnolle, 2017). To properly manage such habitats for bees, the specific nutritional needs of the bee species of interest should be understood. It is insufficient to simply enrich the bee habitat with nectar- and pollen-yielding plants while ignoring the nutritional value of these plants for bee larvae. As the nutritional ecology of wild bees is not well understood, the management of bee habitats, especially actions undertaken to improve their nutritional base, is not effective (Gresty et al., 2018; Wood, Holland, \& Goulson, 2015, 2017). Both the quality and quantity of food sources for bees should be considered in intervention strategies; planting plant species that offer pollen or nectar in large quantities but with random or unknown nutritional quality is not a good practice for improving the nutritional base for bees. For example, lavender pollen was highlighted here as stoichiometrically unbalanced for O. bicornis, yet it is considered one of the most bee-friendly plants (Garbuzov \& Ratnieks, 2014). In addition, the pollen of crops such as rapeseed, sunflower and corn was noted here as unbalanced for O. bicornis (Table S1). Therefore, specific plant species that enable dietary nutritional balance might be planted near areas of crop monocultures to limit the negative influence of these crops on bee production.

Nutrient collapse in plant tissues has been reported in recent studies; specifically, elevated concentrations of atmospheric $\mathrm{CO}_{2}$ have been found to reduce the concentrations of important nutrients in plant tissues (Loladze, 2014), including those in pollen utilized by bees (Ziska et al., 2016). It has also been shown that crop domestication may cause a several-fold decrease in the concentration of floral rewards of nutrients important for pollinators (Egan et al., 2018). Thus, understanding the demand of growing bees for a nutritionally balanced diet is increasingly important.

In conclusion, this study shows that the nutritional needs and nutritional ecology of bees are not as simple as we tend to assume when planning conservation strategies. Bee-friendly plants should not be defined based solely on the quantities of food produced or on the visitation rates of adult insects foraging for energy. To develop effective strategies for bee conservation, larval nutritional needs should be considered and plants providing stoichiometric balancing of the larval diet should be included in wildflower mixes for bees. Ultimately, complementary mixes of plants, allowing the balancing of both adult and larval diets and addressing both sexual and taxonomical differences, should be provided for wild bees. More data are required to inform conservation strategies for wild bees. Such data should include (a) the nutritional requirements of larvae of various wild bees to provide knowledge on bee nutritional demands and (b) the nutritional composition of pollen produced by different plants to provide knowledge on nutritional supply in the environment. Understanding the relationship between (a) and (b) will allow us to develop effective management strategies for maintaining populations of wild bees.

\section{ACKNOWLEDGEMENTS}

I thank Andrzej Antot for his help with $\mathrm{R}$ and PERMANOVA and express my gratitude to the editors and the reviewers. English language editing was performed by American Journal Experts (AJE). The study was supported by the Polish Ministry of Science and Higher Education (grant no. DS/WBiNoZ/INoŚ/DS 761) and the National Science Centre, Poland (grant no. 2016/21/B/ NZ8/00318).

\section{DATA ACCESSIBILITY}

Data available via the Dryad Digital Repository https://doi. org/10.5061/dryad.3jb647c/1 (Filipiak, 2019).

\section{ORCID}

Michat Filipiak (iD https://orcid.org/0000-0001-7438-4885

\section{REFERENCES}

Bartrons, M., Sardans, J., Hoekman, D., \& Peñuelas, J. (2018). Trophic transfer from aquatic to terrestrial ecosystems: A test of the biogeochemical niche hypothesis. Ecosphere, 9, e02338. https://doi. org/10.1002/ecs2.2338

Bradshaw, C., Kautsky, U., \& Kumblad, L. (2012). Ecological stoichiometry and multi-element transfer in a coastal ecosystem. Ecosystems, 15, 591-603. https://doi.org/10.1007/s10021-012-9531-5

Bukovinszky, T., Rikken, I., Evers, S., Wäckers, F. L., Biesmeijer, J. C., Prins, H. H. T., \& Kleijn, D. (2017). Effects of pollen species composition on the foraging behaviour and offspring performance of the mason bee Osmia bicornis (L.). Basic and Applied Ecology, 18, 21-30. https://doi. org/10.1016/j.baae.2016.11.001

Cole, L. J., Brocklehurst, S., Robertson, D., Harrison, W., \& McCracken, D. I. (2017). Exploring the interactions between resource availability and the utilisation of semi-natural habitats by insect pollinators in an intensive agricultural landscape. Agriculture, Ecosystems and Environment, 246, 157-167. https://doi.org/10.1016/j. agee.2017.05.007

Denno, R. F., \& Fagan, W. F. (2003). Might nitrogen limitation promote omnivory among carnivorous arthropods? Ecology, 84, 2522-2531. https://doi.org/10.1890/02-0370

Egan, P. A., Adler, L. S., Irwin, R. E., Farrell, I. W., Palmer-Young, E. C., \& Stevenson, P. C. (2018). Crop domestication alters floral reward chemistry with potential consequences for pollinator health. Frontiers in Plant Science, 9, 1357-1357. https://doi.org/10.3389/ fpls.2018.01357

Filipiak, M. (2018). A better understanding of bee nutritional ecology is needed to optimize conservation strategies for wild bees-the 
application of ecological stoichiometry. Insects, 9, E85. https://doi. org/10.3390/insects9030085

Filipiak, M. (2019). Data from: Key pollen host plants provide balanced diets for wild bee larvae - A lesson for planting flower strips and hedgerows. Dryad Digital Repository, https://doi.org/10.5061/ dryad.3jb647c/1

Filipiak, M., Kuszewska, K., Asselman, M., Denisow, B., Stawiarz, E., Woyciechowski, M., \& Weiner, J. (2017). Ecological stoichiometry of the honeybee: Pollen diversity and adequate species composition are needed to mitigate limitations imposed on the growth and development of bees by pollen quality. PLoS ONE, 12, e0183236. https:// doi.org/10.1371/journal.pone.0183236

Filipiak, M., \& Weiner, J. (2017). Plant-insect interactions: The role of ecological stoichiometry. Acta Agrobotanica, 70, 1-16. https://doi. org/10.5586/aa.1710

Garbuzov, M., \& Ratnieks, F. L. W. (2014). Listmania: The strengths and weaknesses of lists of garden plants to help pollinators. BioScience, 64, 1019-1026. https://doi.org/10.1093/biosci/biu150

González, A. L., Céréghino, R., Dézerald, O., Farjalla, V. F., Leroy, C., Richardson, B. A., ... Srivastava, D. S. (2018). Ecological mechanisms and phylogeny shape invertebrate stoichiometry: A test using detritus-based communities across Central and South America. Functional Ecology, 32, 2448-2463. https://doi. org/10.1111/1365-2435.13197

Gresty, C. E. A., Clare, E., Devey, D. S., Cowan, R. S., Csiba, L., Malakasi, P., ... Willis, K. J. (2018). Flower preferences and pollen transport networks for cavity-nesting solitary bees: Implications for the design of agri-environment schemes. Ecology and Evolution, 8, 7574-7587. https://doi.org/10.1002/ece3.4234

Jachula, J., Denisow, B., \& Wrzesien, M. (2018). Validation of floral food resources for pollinators in agricultural landscape in SE Poland. Journal of the Science of Food and Agriculture, 98, 2672-2680. https:// doi.org/10.1002/jsfa.8761

Jeyasingh, P. D., Cothran, R. D., \& Tobler, M. (2014). Testing the ecological consequences of evolutionary change using elements. Ecology and Evolution, 4, 528-538. https://doi.org/10.1002/ece3.950

Jones, R. H., \& Flynn, K. J. (2005). Nutritional status and diet composition affect the value of diatoms as copepod prey. Science, 307, 1457-1459. https://doi.org/10.1126/science.1107767

Kaluza, B. F., Wallace, H. M., Heard, T. A., Minden, V., Klein, A., \& Leonhardt, S. D. (2018). Social bees are fitter in more biodiverse environments. Scientific Reports, 8, 12353. https://doi.org/10.1038/ s41598-018-30126-0

Kaluza, B. F., Wallace, H., Keller, A., Heard, T. A., Jeffers, B., Drescher, N., ... Leonhardt, S. D. (2017). Generalist social bees maximize diversity intake in plant species-rich and resource-abundant environments. Ecosphere, 8, e01758. https://doi.org/10.1002/ecs2.1758

Kay, A. D., Ashton, I. W., Gorokhova, E., Kerkhoff, A. J., Liess, A., \& Litchman, E. (2005). Toward a stoichiometric framework for evolutionary biology. Oikos, 109, 6-17. https://doi. org/10.1111/j.0030-1299.2005.14048.x

Kay, A. D., \& Vrede, T. (2008). Evolutionary and biochemical aspects. In S. E. Jørgensen, \& B. D. Fath (Eds.), Encyclopedia of ecology (pp. 14721481). Amsterdam: Elsevier.

Leal, M. C., Seehausen, O., \& Matthews, B. (2017). The ecology and evolution of stoichiometric phenotypes. Trends in Ecology and Evolution, 32, 108-117. https://doi.org/10.1016/j.tree.2016.11.006

Leroux, S. J., Wal, E. V., Wiersma, Y. F., Charron, L., Ebel, J. D., Ellis, N. M., ... Yalcin, S. (2017). Stoichiometric distribution models: Ecological stoichiometry at the landscape extent. Ecology Letters, 20, 14951506. https://doi.org/10.1111/ele.12859
Loladze, I. (2014). Hidden shift of the ionome of plants exposed to elevated $\mathrm{CO}_{2}$ depletes minerals at the base of human nutrition. eLife, 3 , e02245. https://doi.org/10.7554/eLife. 02245

Morehouse, N. I., Nakazawa, T., Booher, C. M., Jeyasingh, P. D., \& Hall, M. D. (2010). Sex in a material world: Why the study of sexual reproduction and sex-specific traits should becomemore nutritionally-explicit. Oikos, 119, 766-778. https://doi.org/10.1111/j.1600-0706.2009.18569.x

Oksanen, F. J., Blanchet, G., Friendly, M., Kindt, R., Legendre, P., McGlinn, D., ... Wagner, H. (2019). Vegan: Community ecology package. Retrieved from https://CRAN.R-project.org/package=vegan

$R$ Core Team. (2018). R: A language and environment for statistical computing. Vienna, Austria: R Foundation for Statistical Computing.

Requier, F., Odoux, J.-F., Henry, M., \& Bretagnolle, V. (2017). The carryover effects of pollen shortage decrease the survival of honeybee colonies in farmlands. Journal of Applied Ecology, 54, 1161-1170. https://doi.org/10.1111/1365-2664.12836

Sterner, R. W., \& Elser, J. J. (2002). Ecological stoichiometry: The biology of elements from molecules to the biosphere. Princeton, NJ: Princeton University Press.

Sterner, R. W., \& Elser, J. J. (2008). Ecological stoichiometry: Overview. In S. E. Jørgensen, \& B. D. Fath (Eds.), Encyclopedia of ecology (pp. 1101-1116). Amsterdam: Elsevier.

Strachecka, A., Chobotow, J., Paleolog, J., Los, A., Schulz, M., Teper, D., ... Grzybek, M. (2017). Insights into the biochemical defence and methylation of the solitary bee Osmia rufa L: A foundation for examining eusociality development. PLOS ONE, 12, e0176539. https://doi. org/10.1371/journal.pone.0176539

Vaudo, A. D., Tooker, J. F., Grozinger, C. M., \& Patch, H. M. (2015). Bee nutrition and floral resource restoration. Current Opinion in Insect Science, 10, 133-141. https://doi.org/10.1016/j.cois.2015.05.008

Warzecha, D., Diekötter, T., Wolters, V., \& Jauker, F. (2018). Attractiveness of wildflower mixtures for wild bees and hoverflies depends on some key plant species. Insect Conservation and Diversity, 11, 32-41. https://doi.org/10.1111/icad.12264

Wood, T. J., Holland, J. M., \& Goulson, D. (2015). Pollinator-friendly management does not increase the diversity of farmland bees and wasps. Biological Conservation, 187, 120-126. https://doi.org/10.1016/j. biocon.2015.04.022

Wood, T. J., Holland, J. M., \& Goulson, D. (2017). Providing foraging resources for solitary bees on farmland: Current schemes for pollinators benefit a limited suite of species. Journal of Applied Ecology, 54, 323-333. https://doi.org/10.1111/1365-2664.12718

Ziska, L. H., Pettis, J. S., Edwards, J., Hancock, J. E., Tomecek, M. B., Clark, A., ... Polley, H. W. (2016). Rising atmospheric $\mathrm{CO}_{2}$ is reducing the protein concentration of a floral pollen source essential for North American bees. Proceedings of the Royal Society. Series B: Biological Sciences, 283, 20160414. https://doi.org/10.1098/rspb.2016.0414

\section{SUPPORTING INFORMATION}

Additional supporting information may be found online in the Supporting Information section at the end of the article.

How to cite this article: Filipiak M. Key pollen host plants provide balanced diets for wild bee larvae: A lesson for planting flower strips and hedgerows. J Appl Ecol. 2019;00: 1-9. https://doi.org/10.1111/1365-2664.13383 